\title{
ANALISIS TINGKAT RISIKO PEMBIAYAAN MURABAHAH, TINGKAT RISIKO PEMBIAYAAN MUSYARAKAH, FINANCING TO DEPOSIT RATIO (FDR) DAN PENGARUHNYA TERHADAP PROFITABILITAS PADA BANK PEMBIAYAAN RAKYAT SYARIAH
}

\author{
Masturo \\ anugrah.alan@yahoo.com \\ Dosen Fakultas Ekonomi dan Bisnis, Universitas Muhammadiyah Tangerang \\ Samino Hendrianto \\ samhendrian75@gmail.com
}

Dosen Fakultas Ekonomi dan Bisnis, Universitas Muhammadiyah Tangerang

\begin{abstract}
ABSTRAK
Analisis Tingkat Risiko Pembiayaan Murabahah, Musyarakah, Financing to Deposit Ratio (FDR) dan Pengaruhnya Terhadap Profitabilitas pada Bank Pembiayaan Rakyat Syariah Periode 2015-2017 yang telah di publikasikan oleh BI dan OJK

Teknik sampel yang digunakan adalah purposive sampling sehingga diperoleh jumlah sampel sebanyak 3 BPRS yaitu Bank Pembiayaan Rakyat Syariah (BPRS) Amanah Rabbaniah Bandung, BPRS Berkah Ramadhan Tangerang, dan BPRS HIK Tangerang. Teknik analisis yang digunakan dalam penelitian ini adalah regresi linear berganda. Hasil penelitian ini menyatakan bahwa secara parsial risiko pembiayaan murabahah (NPF murabahah) dan Financing to Deposit Ratio (FDR) memiliki pengaruh yang positif dan signifikan terhadap profitabilitas. Sedangkan risiko pembiayaan musyarakah (NPF musyarakah) memiliki pengaruh negatif dan signifikan terhadap profitabilitas.
\end{abstract}

Kata Kunci: Risiko Pembiayaan Murabahah (NPF Murabahah), Risiko Pembiayaan Musyarakah (NPF Musyarakah), Financing to Deposit Ratio (FDR), Profitabilitas (ROA).

\section{PENDAHULUAN}

Bank Pembiayaan Rakyat Syariah (BPRS) adalah perbankan yang beroperasi dalam sekala kecil, diperuntukkan melayani Usaha Kecil dan Mikro (UKM), serta tidak diperkenankan melayani simpanan dalam bentuk rekening giro. BPRS beroperasi pada wilayah kabupaten ataupun kotamadya dengan jangkauan yang terbatas sebagaimana permodalannya yang relatif kecil. Dasar hukum dari Bank
Pembiayaan Rakyat Syariah ini mengacu pada peraturan Bank Indonesia No.11/23/PBI/2009 yaitu Bank Pembiayaan Rakyat Syariah sebagai salah satu lembaga kepercayaan masyarakat yang kegiatan usahanya berdasarkan prinsip syariah, dituntut agar selalu dapat mengemban amanah dari para pemilik dana dengan cara menyalurkannya untuk usaha produktif dalam rangka meningkatkan taraf hidup 
masyarakat. Bank Pembiayaan Rakyat Syariah perlu memperhatikan kinerja keuangan untuk menilai citra baik dan buruknya suatu perbankan. Kinerja keuangan merupakan gambaran kondisi keuangan bank pada periode tertentu baik menyangkut aspek penghimpunan dana maupun penyaluran dana yang salah satunya dapat diukur dengan indikator profitabilitas.

Profitabilitas merupakan salah satu alat analisis keuangan bank yang mengukur kesuksesan manajemen dalam menghasilkan laba atau keuntungan dari operasi usaha bank. Profitabilitas yang tinggi dapat menunjukkan kinerja keuangan bank yang baik. Sebaliknya jika profitabilitas atau pendapatan yang dicapai rendah, mengindikasi kurang maksimalnya kinerja keuangan manajemen dalam menghasilkan laba. Sumber utama pendapatan atau keuntungan pada Bank Pembiayaan Rakyat Syariah berasal dari penyaluran dana.Dana yang di salurkan itu adalah dana-dana yang berasal dari pihak ke tiga.Untuk melihat apakah dana pihak ketiga sudah berjalan efektif atau belum maka indikator yang dapat di gunakan adalah FDR (Financing to Deposit Ratio). Semakin tinggi FDR (Financing to Deposit Ratio) memberikan indikasi semakin tinggi dana yang disalurkan ke dana pihak ketiga.

Penyaluran dana yang diberikan oleh bank kepada pihak ketiga biasanya disalurkan untuk pembiayaan. Karena pembiayaan merupakan komponen aset produktif yang kegiatannya memberikan fasilitas keuangan dari satu pihak kepada pihak lain untuk mendukung kelancaran usaha maupun untuk investasi yang telah direncanakan.

Tidak dapat dipungkiri, tentunya terdapat risiko dalam pelaksanaan pembiayaan. Risiko pembiayaan mengacu pada potensi kerugian yang dihadapi lembaga keuangan ketika pembiayaan yang diberikannya macet. Debitur mengalami kondisi ini ketika dia tidak mampu memenuhi kewajiban mengembalikan modal yang diberikan oleh bank maupun menyerahkan porsi keuntunganyang seharusnya diperoleh bank. Risiko pembiayaan murabahah dan musyarakah diukur dengan menggunakan rasio Non Performing Financing (NPF). Selain pembiayaan bermasalah bank juga harus memperhatikan FDR (Financing to Deposit Ratio). Semakin tinggi dana yang tersalurkan (FDR) pada perbankan syari'ah, akan mengorbankan tingkat pendapatan atau profitabilitas dan jika terlalu sedikit akan berpotensi meningkatkan biaya dan akhirnya menurunkan profitabilitas.

Berdasarkan latar belakang, maka yang menjadi pokok permasalahan dalam penelitian penulis adalah sebagai berikut: (1) Apakah tingkat risiko pembiayaan murabahah berpengaruh terhadap profitabilitas?; (2) Apakah tingkat risiko pembiayaan musyarakah berpengaruh terhadap profitabilitas?; (3) Apakah Financing to Deposit Ratio (FDR) berpengaruh terhadap profitabilitas?.

Sesuai dengan latar belakang dan rumusan masalah, maka yang menjadi tujuan dalam penelitian penulis adalah sebagai berikut: (1) Untuk mengetahui pengaruh tingkat 
risiko pembiayaan murabahah terhadap profitabilitas; (2) Untuk mengetahui pengaruh tingkat risiko pembiayaan musyarakah terhadap profitabilitas; (3) Untuk mengetahui pengaruh Financing to Deposit Ratio (FDR) terhadap profitabilitas.

Berdasarkan latar belakang, rumusan masalah dan tujuan penelitian maka penelitian penulis diharapkan dapat memberikan manfaat penelitian adalah sebagai sebagai berikut: Pertama. Manfaat Teoritis. Hasil penelitian diharapkan dapat digunakan sebagai masukan, tambahan wawasan, dan bukti empiris mengenai Analisis Tingkat Risiko Pembiayaan Murabahah, Musyarakah, Financing to Deposit Ratio (FDR) dan Pengaruhnya Terhadap Profitabilitas serta dapat dijadikan sebagai bahan referensi bagi peneliti yang akan melakukan penelitian sejenis dan lebih lanjut. Kedua. Manfaat Praktis. Penelitian ini diharapkan dapat memberi informasi yang bermanfaat bagi pembaca khususnya investor atau para pemegang saham dalam pengambilan keputusan.

\section{KAJIAN PUSTAKA}

\section{Teori Pensinyalan (Signalling}

\section{Theory)}

Teori signalling menjelaskan bahwa pemberian sinyal dilakukan oleh manajemen untuk mengurangi asimetri informasi. Teori sinyal ini membahas bagaimana seharusnya sinyal-sinyal keberhasilan atau kegagalan manajemen disampaikan kepada pemilik. Dalam kondisi keuangan perusahaan buruk, manajemen melakukan manajemen laba untuk memberikan sinyal kabar buruk dengan tujuan memberikan informasi kepada pasar bahwa mereka mempunyai integritas, bertindak jujur, dan mempunyai keyakinan dapat mengatasi masalah yang dihadapi.

Signaling Theory ialah teori yang menyatakan adanya dorongan yang dimiliki oleh para manajer perusahaan yang memiliki informasi yang baik mengenai perusahaan, sehingga para manajer akan terdorong untuk dapat menyampaikan informasi mengenai perusahaan tersebut kepada para calon investor, yang bertujuan agar perusahaan dapat meningkatkan nilai perusahaan tersebut melalui sinyal dalam pelaporan pada laporan tahunan perusahaan (Leland dan Pyle, 1977 dalam Resa Rusar, 2017). Teori Pensinyalan memotivasi para manajer perbankan khususnya pada saat menyalurkan kredit. Motivasi yang dimiliki oleh para manajer bank khususnya perbankan syariah dalam memberikan informasi ditujukan agar dapat memberikan berbagai macam informasi kepada pihak debitur, sehingga para investor dapat mengindikasikan bahwa pihak bank dalam menyalurkan kredit dengan melihat terlebih dahulu kondisi perusahaan dan calon debitur sehingga nantinya dapat menyalurkan kredit dengan tepat sasaran.

\section{Penelitian Terdahulu}

Putra (2012), menunjukkan bahwa perputaran kas, perputaran piutang berpengaruh signifikan terhadap profitabilitas. Penelitian tersebut diperkuat oleh Wijaya (2012) dimana komponen modal kerja tersebut mempunyai pengaruh yang signifikan terhadap profitabilitas. 
Verawati (2014), faktor yang mempengaruhi profitabilitas adalah rasio perputaran piutang dan perputaran persediaan sedangkan perputaran modal kerja tidak berpengaruh. Iriani Santoso (2014), yang menyimpulkan perputaran piutang tidak berpengaruh terhadap profitabilitas

Putri Ayu Diana dan Bambang Hadi Santoso (2016), perputaran kas berpengaruh signifikan terhadap profitabilitas. perputaran kas, perputaran piutang dan perputaran persediaan berpengaruh signifikan terhadap profitabilitas pada perusahaan cement di Bursa Efek Indonesia, menyimpulkan bahwa menunjukkan perputaran kas berpengaruh signifikan terhadap profitabilitas, sedang perputaran piutang dan perputaran persediaan tidak berpengaruh signifikan terhadap profitabilitas.

\section{Model Konseptual Penelitian}

Dari latar belakang permasalahan serta tinjauan teoritis yang muncul maka model konseptual sebagai berikut:

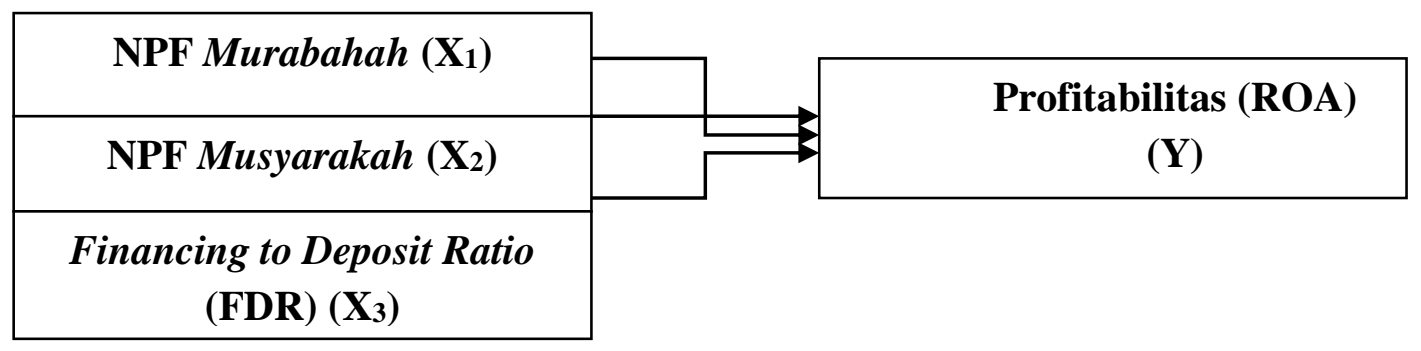

Gambar 1

Model Konseptual Penelitian

\section{Perumusan Hipotesis}

Pengaruh NPF Murabahah (X1) terhadap Profitabilitas (ROA)

Risiko yang terjadi pada bank syariah dalam memberikan fasilitas pembiayaan adalah tidak kembalinya pokok pembiayaan dan tidak mendapat imbalan, ujrah, atau bagi hasil sebagaimana telah disepakati dalam akad pembiayaan antara bank syariah dan nasabah penerima fasilitas. Risiko pembiayaan murabahah digunakan untuk mengukur kesehatan kualitas aset bank dengan menggunakan rasio NPF murabahah. Apabila nilai NPF murabahah semakin tinggi (diatas 5\%) maka bank tersebut tidak sehat. NPF yang tinggi menurunkan laba yang akan diterima oleh bank.
Penelitian yang dilakukan Zuliana Roviqoh, S.E.I (2015), yang berjudul "Pengaruh Tingkat Risiko Pembiayaan Murabahah, Mudharabah dan Musyarakah terhadap Tingkat Profitabilitas 20102014", menyimpulkan bahwa NPF murabahah berpengaruh signifikan terhadap profitabilitas (ROA). Berdasarkan paparan di atas dapat dirumuskan hipotesis sebagai berikut.

H1 : Terdapat pengaruh positif dan signifikan NPF Murabahah (X1) terhadap Profitabilitas (ROA) 
Pengaruh NPF Musyarakah (X2) terhadap Profitabilitas (ROA)

Penggunaan model pembiayaan musyarakah yang lebih besar pada sisi aset akan mengakibatkan ketidakstabilan sistemik pada saat giro dipergunakan dalam jumlah besar oleh bank syariah, hal ini akan meningkatkan risiko pembiayaan musyarakah. Risiko pembiayaan musyarakah digunakan untuk mengukur kesehatan kualitas aset bank dengan menggunakan rasio NPF musyarakah. Apabila nilai NPF musyarakah semakin tinggi (diatas 5\%) maka bank tersebut tidak sehat. NPF yang tinggi menurunkan laba yang akan diterima oleh bank.

Penelitian yang dilakukan Fauzan Fahrul, Muhammad Arfan, Darwanis (2012), yang berjudul "Pengaruh Tingkat Risiko Pembiayaan Musyarakah Dan Pembiayaan Murabahah Terhadap Tingkat Profitabilitas Bank Syariah menyimpulkan bahwa risiko pembiayaan musyarakah berpengaruh terhadap tingkat profitabilitas bank syariah. Berdasarkan paparan di atas dapat dirumuskan hipotesis sebagai berikut.

H2 : Terdapat pengaruh positif dan signifikan NPF Musyarakah (X2) terhadap Profitabilitas (ROA)

Pengaruh Financing to Deposite Ratio (FDR) (X3) terhadap Profitabilitas (ROA)

Financing to Deposite Ratio (FDR) merupakan alat ukur untuk mengukur besarnya volume pembiayaan sehingga rasio FDR ini dapat menunjukan kesehatan bank dalam memberikan pembiayaannya.
Pada penelitian Bambang Agus Pramuka, menjelaskan semakin tinggi FDR mengindikasikan bahwa sebuah bank lebih menekankan keuangannya pada penyaluran hutang atau pembiayaan yang lebih banyak. Semakin kecil FDR semakin baik likuiditas bank tersebut. ${ }^{1}$

Penelitian yang dilakukan Bambang Agus Pramuka (2010), yang berjudul "Faktor-Faktor yang Berpengaruh Terhadap Tingkat Profitabilitas Bank Umum Syariah", menyimpulkan bahwa FDR berpengaruh positif terhadap profitabilitas (ROA) bank umum syariah. Berdasarkan paparan di atas dapat dirumuskan hipotesis sebagai berikut.

H3 : Terdapat pengaruh positif dan signifikan Financing to Deposite Ratio (FDR) (X3) terhadap Profitabilitas (ROA) 


\section{METODE PENELITIAN \\ Populasi dan Sampel Penelitian}

Penelitian dilakukan pada

Bank Pembiayaan Rakyat Syariah (BPRS) Amanah Rabbaniah Bandung, BPRS Berkah Ramadhan Tangerang, dan BPRS HIK Tangerang Periode 2015-2017. Jenis data yang digunakan dalam penelitian ini adalah data sekunder. Data sekunder merupakan data yang diperoleh dalam bentuk yang sudah jadi, sudah dikumpulkan dan diolah oleh pihak lain dan sudah dalam bentuk publikasi. Sumber data dalam penelitian ini bersumber dari laporan keuangan triwulan Bank Pembiayaan Rakyat Syariah (BPRS) Amanah Rabbaniah Bandung,BPRS Berkah Ramadhan Tangerang, BPRS HIK Tangerang. Dengan data triwulan periode 2015 sampai dengan 2017 yang telah di publikasikan oleh BI dan OJK.

Teknik penentuan sampel dalam penelitian ini menggunakan purposive sampling, yang artinya BPRS yang akan dijadikan sampel penelitian ini dipilih menggunakan pertimbangan dengan memasukkan unsur-unsur tertentu yang dianggap memiliki kriteria; (1) Bank Pembiayaan Rakyat Syariah yang terdaftar di BI maupun OJK; (2) Bank Pembiayaan Rakyat Syariah yang mengeluarkan laporan keuangan triwulan yang lengkap untuk mengetahui informasi variabel independen yang diteliti; (3) Bank Pembiayaan Rakyat Syariah yang melakukan akad pembiayaan murabahah dan musyarakah; (4) Bank Pembiayaan Rakyat Syariah yang mempunyai NPF yang tinggi diatas 5\%; (5) Bank Pembiayaan Rakyat Syariah yang mempunyai
FDR yang sangat tinggi maupun terlalu rendah; (6) Bank Pembiayaan Rakyat Syariah di Provinsi Jawa Barat dan Banten.

\section{Teknik Pengumpulan Data}

Teknik pengumpulan data dalam penelitian ini dengan sebagai berikut: (1) Field Research: Data tersebut berupa sumber data sekunder yang diambil dari laporan keuangan triwulan Bank Pembiayaan Rakyat Syariah (BPRS) Amanah Rabbaniah Bandung,BPRS Berkah Ramadhan Tangerang, BPRS HIK Tangerang periode 2014 -2017 yang dipublish oleh Bank Indonesia (BI) dan Otoritas Jasa Keuangan (OJK); (2) Library Research: Metode pengumpulan data dengan cara mempelajari dan memahami bukubuku yang berhubungan dengan manajemen keuangan, risiko pembiayaan bank syariah, FDR dan profitabilitas bank syariah, serta jurnal dan hasil penelitian yang diperoleh dari berbagai sumber yang berhubungan atau mendukung penelitian ini.

\section{HASIL DAN PEMBAHASAN Statistik Deskriptif}

Hasil statistik deskriptif pengujian pengaruh Analisis Tingkat Risiko Pembiayaan Murabahah, Musyarakah, Financing to Deposit Ratio (FDR) dan Pengaruhnya Terhadap Profitabilitas (ROA) disajikan sebagai berikut: 
Tabel 1

Statistik Deskriptif

\begin{tabular}{|l|r|r|r|r|r|}
\hline & $\mathrm{N}$ & Minimum & Maximum & \multicolumn{1}{c|}{ Mean } & \multicolumn{1}{c|}{ Std. Deviation } \\
\hline X1 & 36 & .35 & 8.16 & 3.6372 & 2.23751 \\
X2 & 36 & .32 & 5.62 & 2.1925 & 1.06263 \\
X3 & 36 & 68.21 & 117.00 & 90.6211 & 13.39029 \\
Y & 36 & .33 & 4.95 & 2.9847 & 1.41641 \\
Valid N (listwise) & 36 & & & & \\
\hline
\end{tabular}

Berdasarkan hasil perhitungan terdiri dari 3 BPRS dengan sampel masingmasing variable sebanyak 36 pengamatan, nilai rata-rata sebagai berikut:

Risiko Pembiayaan Murabahah (NPF Murabahah) (X1) sebesar 3.6372 dengan standar deviasi 2.23751, jarak antara nilai minimum dan maximum dari sebagai berikut: Risiko Pembiayaan Murabahah (NPF Murabahah) (X1) dimana nilai minimum sebesar 0.35 dan nilai maksimum sebesar 8.16.

Nilai rata-rata Risiko Pembiayaan Musyarakah (NPF Musyarakah) (X2) sebesar 2.1925 dengan standar deviasi 1.06263, jarak antara nilai minimum dan maximum dari Risiko Pembiayaan Musyarakah (NPF Musyarakah) (X2) dimana nilai minimum sebesar 0.32 dan nilai maksimum sebesar 5.62.

Nilai rata-rata Financing to Deposit Ratio (FDR) (X3) sebesar 90.6211 dengan standar deviasi 13.39029, jarak antara nilai minimum dan maximum dari Financing to Deposit Ratio (FDR) (X3) dimana nilai minimum sebesar 68.21 dan nilai maksimum sebesar 117.00.

\section{Uji Asumsi Klasik. Uji Normalitas}

Tujuan Uji normalitas untuk menguji apakah model regresi, variable pengganggu atau residual mempunyai distribusi normal atau tidak. Statistik uji yang digunakan untuk menguji normalitas adalah One - Sample Kolmogorov - Smirnov $(K-S)$ Test seperti yang ditunjukkan pada Tabel sebagai berikut berikut:

Tabel 2

Uji Normalitas

\begin{tabular}{|ll|r|r|r|}
\hline & & $X 1$ & $X 2$ & \multicolumn{1}{|c|}{ X3 } \\
\hline $\mathrm{N}$ & & 36 & 36 & 36 \\
Normal Parameters ${ }^{\mathrm{a}, \mathrm{b}}$ & Mean & 3.6372 & 2.1925 & 90.6211 \\
& Std. Deviation & 2.23751 & 1.06263 & 13.39029 \\
Most Extreme Differences & Absolute & .173 & .272 & .158 \\
& Positive & .173 & .272 & .158 \\
& Negative & -.093 & -.168 & -.097 \\
Test Statistic & & .173 & .272 & .158 \\
Asymp. Sig. (2-tailed) & & $.008^{\mathrm{c}}$ & $.000^{\mathrm{c}}$ & $.023^{\mathrm{c}}$ \\
\hline
\end{tabular}

Pengujian normalitas dengan Murabahah (NPF Murabahah) menggunakan uji KolmogorovSmirnov menunjukkan tingkat (X1) sebesar 0.08, Risiko signifikansi Risiko Pembiayaan Pembiayaan Musyarakah (NPF Musyarakah) (X2) sebesar 0.00, dan 
Financing to Deposit Ratio (FDR) (X3) sebesar 0.023. Signifikansi ketiga variable tersebut menunjukkan lebih kecil dari angka 0,05, maka penulis menyimpulkan bahwa model regresi yang digunakan memiliki distribusi data normal.

\section{Uji Multilikioner}

Tujuan Uji multikolinearitas adalah untuk menguji apakah model regresi ditemukan adanya korelasi antarvariabel bebas. Hasil uji multikolinearitas dapat dilihat dari nilai tolerance dan variance inflaction factor (VIF) seperti yang ditunjukkan pada table 3 .
Hasil pengujian yang ditunjukkan pada tabel, nilai tolerance yaitu Risiko Pembiayaan Murabahah (NPF Murabahah) $(\mathrm{X} 1)=0.112$, Risiko Pembiayaan Musyarakah (NPF Musyarakah) $(\mathrm{X} 2)=0.884$, dan Financing to Deposit Ratio (FDR) $\quad(\mathrm{X} 3)=0.732, \quad$ yang merupakan variabel bebas, karena nilai variance inflation factor (VIF) $=1$.

Kesimpulannya, nilai tolerance lebih kecil dari nilai variance inflation factor (VIF) berarti tidak ada multikolineritas antarvariabel bebas.

Tabel 3

Uji Multikolinearitas

\begin{tabular}{|c|c|c|c|c|}
\hline & & $\mathrm{X} 1$ & $\mathrm{x} 2$ & $\mathrm{X} 3$ \\
\hline \multirow[t]{3}{*}{$\mathrm{X} 1$} & Pearson Correlation & 1 & -.025 & -.269 \\
\hline & Sig. (2-tailed) & & .884 & .112 \\
\hline & $\mathrm{N}$ & 36 & 36 & 36 \\
\hline \multirow[t]{3}{*}{$\mathrm{X} 2$} & Pearson Correlation & -.025 & 1 & -.059 \\
\hline & Sig. (2-tailed) & .884 & & .732 \\
\hline & $\mathrm{N}$ & 36 & 36 & 36 \\
\hline \multirow[t]{3}{*}{$\mathrm{X3}$} & Pearson Correlation & -.269 & -.059 & 1 \\
\hline & Sig. (2-tailed) & .112 & .732 & \\
\hline & $\mathrm{N}$ & 36 & 36 & 36 \\
\hline \multicolumn{2}{|c|}{ Uji Autokorelasi } & dapat & mengetahui & adanya \\
\hline \multicolumn{2}{|c|}{$\begin{array}{l}\text { Tujuan Uji autokorelasi adalah untuk } \\
\text { menguji apakah dalam suatu model } \\
\text { regresi ada korelasi antara kesalahan } \\
\text { pengganggu pada perioda } t \text { dengan }\end{array}$} & \multicolumn{3}{|c|}{$\begin{array}{l}\text { autokorelasi dilakukan dengan } \\
\text { metode Durbin-Watson (DW). Hasil } \\
\text { uji DW dapat dilihat pada tabel } \\
\text { sebagai berikut: }\end{array}$} \\
\hline
\end{tabular}

kesalahan pada perioda t-1. Untuk

Tabel 4

Uji Autokorelasi

\begin{tabular}{|c|c|c|c|c|c|}
\hline Model & $\mathrm{R}$ & R Square & Adjusted R Square & Std. Error of the Estimate & Durbin-Watson \\
\hline 1 & $.770^{\mathrm{a}}$ & .593 & .555 & .94504 & 1.366 \\
\hline
\end{tabular}

Adjusted R Square $=0.555$ dan nilai

Durbin-Watson $=1366$. Penulis

menyimpulkan bahwa pengujian 


\section{Uji Heteroskedastisitas}

Tujuan Uji heteroskedastisitas adalah untuk menguji apakah dalam model regresi terjadi ketidaksamaan variance dari residual suatu pengamatan ke pengamatan yang lain. Pengujian heteroskedastisitas pada penelitian menunjukkan bahwa Risiko Pembiayaan Murabahah (NPF Murabahah) (X1) sebesar 0.311, Risiko Pembiayaan Musyarakah (NPF Musyarakah) (X2) sebesar -0,255, dan Financing to Deposit Ratio (FDR) (X3) sebesar 0.073. Pembiayaan Murabahah (NPF Murabahah) (X1) dan Financing to Deposit Ratio (FDR) (X3) berpengaruh pada nilai absolut residual yaitu ketiga variable lebih besar 0.05 berarti model regresi tersebut bebas heteroskedastisitas. Risiko Pembiayaan Musyarakah (NPF Musyarakah) (X2) lebih kecil 0,05 berarti model regresi tersebut heteroskedastisitas.

Tabel 5

Uji Heteroskedastisitas

\begin{tabular}{|c|c|c|c|c|c|c|}
\hline \multirow{2}{*}{\multicolumn{2}{|c|}{ Model }} & \multicolumn{2}{|c|}{ Unstandardized Coefficients } & \multirow{2}{*}{$\begin{array}{c}\text { Standardized } \\
\text { Coefficients } \\
\text { Beta }\end{array}$} & \multirow[b]{2}{*}{$\mathrm{t}$} & \multirow[b]{2}{*}{ Sig. } \\
\hline & & $\mathrm{B}$ & Std. Error & & & \\
\hline \multirow[t]{4}{*}{1} & (Constant) & -4.211 & 1.302 & & -3.234 & .003 \\
\hline & $\mathrm{X} 1$ & .311 & .074 & .491 & 4.188 & .000 \\
\hline & $\mathrm{X} 2$ & -.255 & .151 & -.191 & -1.693 & .100 \\
\hline & X3 & .073 & .012 & .691 & 5.889 & .000 \\
\hline
\end{tabular}

Uji Kelayakan Model • Uji Koefesien Determinasi

Tujuan Uji koefesien determinasi adalah untuk menguji apakah dalam suatu model regresi ada korelasi antara kesalahan pengganggu pada perioda $\mathrm{t}$ dengan kesalahan pada perioda t-1. Untuk dapat mengetahui adanya autokorelasi dilakukan dengan metode Durbin-Watson (DW).

Tabel 6

Uji Koefesien Determinasi

\begin{tabular}{|l|c|r|r|r|r|}
\hline Model & $\mathrm{R}$ & $\mathrm{R}$ Square & Adjusted R Square & Std. Error of the Estimate & Durbin-Watson \\
\hline 1 & $.770^{\mathrm{a}}$ & .593 & .555 & .94504 & 1.366 \\
\hline
\end{tabular}

Hasil perhitungan diperoleh nilai koefesien determinasi Adjusted $R$ Square sebesar 0.555. Hal ini menunujukkan bahwa Risiko

Pembiayaan Murabahah (NPF Murabahah) (X1), Risiko Pembiayaan Musyarakah (NPF Musyarakah) (X2), dan Financing to Deposit Ratio (FDR) (X3) berpengaruh dan signifikan terhadap
Profitabilitas (ROA) yang dapat diterangkan oleh model summary yaitu sebesar $55.5 \%$ sedangkan sisanya sebesar $44.5 \%$ dipengaruhi oleh factor-faktor lain yang tidak dimasukkan dalam model regresi.

\section{Uji Signifikasi F}

Tujuan Uji signifikasi f adalah untuk mengetahui pengaruh variable 
independen secara bersama-sama terhadap variable dependen. Uji signifikansi f dapat dilihat pada table sebagai berikut:

Table 7

\section{Hasil Perhitungan Uji F}

\begin{tabular}{|ll|r|r|r|r|r|}
\hline Model & & Sum of Squares & Df & Mean Square & F & Sig. \\
\hline 1 & Regression & 41.639 & 3 & 13.880 & 15.541 & $.000^{\mathrm{b}}$ \\
& Residual & 28.579 & 32 & .893 & & \\
& Total & 70.218 & 35 & & & \\
\hline
\end{tabular}

Hasil analisis dapat diketahui pula bahwa secara bersama-sama variable independen memiliki pengaruh yang signifikan terhadap variable dependen. Hal ini dapat dibuktikan dari nilai $\mathrm{F}$ hitung sebesar 15.541 dengan probabilitas 0,00 atau $0 \%$, karena probabilitas lebih kecil dari tingkat signifikansi yang digunakan 5\%, maka model regresi dapat digunakan untuk memprediksi Profitabilitas (ROA). Hal ini menunujukkan bahwa Risiko Pembiayaan Murabahah (NPF Murabahah) (X1), Risiko Pembiayaan Musyarakah (NPF Musyarakah) (X2), dan Financing to Deposit Ratio (FDR) (X3) secara bersama-sama berpengaruh signifikan terhadap Profitabilitas (ROA).

\section{Uji Hipotesis}

Uji hipotesis yang digunakan dalam penelitian ini adalah uji statistic t. Uji statistic $\mathrm{t}$ bertujuan untuk mengetahui masing-masing variable Risiko Pembiayaan Murabahah (NPF Murabahah) (X1), Risiko Pembiayaan Musyarakah (NPF Musyarakah) (X2), dan Financing to Deposit Ratio (FDR) (X3) berpengaruh terhadap Profitabilitas (ROA). Hasil uji t dapat dilihat pada table 8 sebagai berikut:

Table 8

Hasil Perhitungan Uji T

\begin{tabular}{|c|c|c|c|c|c|c|}
\hline \multirow{2}{*}{\multicolumn{2}{|c|}{ Model }} & \multicolumn{2}{|c|}{ Unstandardized Coefficients } & $\begin{array}{c}\text { Standardized } \\
\text { Coefficients }\end{array}$ & \multirow[b]{2}{*}{$t$} & \multirow[b]{2}{*}{ Sig. } \\
\hline & & $\mathrm{B}$ & Std. Error & Beta & & \\
\hline \multirow[t]{4}{*}{1} & (Constant) & -4.211 & 1.302 & & -3.234 & .003 \\
\hline & $\mathrm{X} 1$ & .311 & .074 & .491 & 4.188 & .000 \\
\hline & $\mathrm{X} 2$ & -.255 & .151 & -.191 & -1.693 & .100 \\
\hline & X3 & .073 & .012 & .691 & 5.889 & .000 \\
\hline
\end{tabular}


Dari Tabel diatas maka dapat disusun persamaan regresi linear berganda sebagai berikut:

$\mathrm{Y}=-4.211+0.311 \mathrm{X} 1-0.255 \mathrm{X} 2+$
$0.073 \mathrm{X} 3+£$

\section{Pengaruh Risiko Pembiayaan} Murabahah (NPF Murabahah) (X1) Terhadap Profitabilitas (ROA)

Hasil pengujian hipotesis menunjukkan bahwa Risiko Pembiayaan Murabahah (NPF Murabahah) (X1) berpengaruh positif dan signifikan secara statistik terhadap Profitabilitas (ROA). Berdasarkan table hasil perhitungan uji $\mathrm{t}$ dapat dilihat nilai signifikansi hitung sebesar 0.311. Karena nilai t hitung lebih besar dari angka signifikan 0,05 yang merupakan angka derajat kepercayaan.

Pengaruh Risiko Pembiayaan Musyarakah (NPF Musyarakah) (X2) Terhadap Profitabilitas (ROA)

Hasil pengujian hipotesis menunjukkan bahwa Risiko Pembiayaan Musyarakah (NPF Musyarakah) (X2) berpengaruh negatif dan signifikan secara statistik terhadap Profitabilitas (ROA). Berdasarkan table hasil perhitungan uji $\mathrm{t}$ dapat dilihat nilai signifikansi hitung sebesar -0,255. Karena nilai t hitung lebih besar dari angka signifikan 0,05 yang merupakan angka derajat kepercayaan.

\section{Pengaruh Financing to Deposit Ratio (FDR) (X3) Terhadap Profitabilitas (ROA)}

Hasil pengujian hipotesis menunjukkan bahwa Financing to Deposit Ratio (FDR) (X3) berpengaruh positif dan signifikan

\section{DAFTAR PUSTAKA}

Bambang Agus Pramuka, "Faktor-Faktor yang Berpengaruh Terhadap
Tingkat Profitabilitas Bank Umum
Syariah", Jurnal Akuntansi,
Manajemen Bisnis dan Sektor
Publik, 2010. terhadap Profitabilitas (ROA). Berdasarkan tabel hasil perhitungan uji $\mathrm{t}$ dapat dilihat nilai signifikansi hitung sebesar 0.073 Karena nilai t hitung lebih besar dari angka signifikan 0,05 yang merupakan angka derajat kepercayaan.

\section{SIMPULAN DAN SARAN}

Simpulan. Berdasarkan hasil pengujian hipotesis, maka diperoleh kesimpulan bahwa variabel Risiko Pembiayaan Murabahah (NPF Murabahah) (X1) dan Financing to Deposit Ratio (FDR) (X3) berpengaruh positif dan signifikan terhadap Profitabilitas (ROA), sedangkan variable Risiko Pembiayaan Musyarakah (NPF Musyarakah) (X2) berpengaruh negative dan signifikan terhadap Profitabilitas (ROA) pada Bank Pembiayaan Rakyat Syariah (BPRS) Amanah Rabbaniah Bandung,BPRS Berkah Ramadhan Tangerang, dan BPRS HIK Tangerang Periode 2015-2017.

Saran. (1) Penelitian selanjutnya dapat menambahkan faktor-faktor lain, sehingga dapat diketahui faktor-faktor lain yang berpengaruh terhadap Profitabilitas (ROA); (2) Penelitian selanjutnya dapat memperpanjang periode pengamatan dan menggunakan keseluruhan populasi di pada Bank Pembiayaan Rakyat Syariah, sehingga lebih mewakili perhitungan secara signifikan; (3) Penelitian selanjutnya, dapat melakukan penelitian dengan ruang lingkup penelitian yang lebih luas ke jenis-jenis bank lainnya, sehingga dapat diketahui perbedaanperbedaan hasil penelitian dari jenis-jenis bank yang berbeda.

Bank Indonesia, lampiran surat edaran Bank Indonesia No.13/24/DPNP, 20011.

Fauzan Fahrul, Muhammad Arfan, Darwanis, "Pengaruh Tingkat Risiko Pembiayaan Musyarakah Dan Pembiayaan Murabahah 
Terhadap Tingkat Profitabilitas Bank Syariah”, Jurnal Akuntansi, Pascasarjana Universitas Syiah Kuala 2012

Fatwa Dewan Syariah Nasional (DSN) No. 04/DSN-MUI/IV/2000, Tentang Murabahah.

http://www.bi.go.id/id/publikasi/laporanke uangan/bank/bprsyariah/Default.as

px

http://www.ojk.go.id/id/kanal/perbankan/d ata-dan-statistik/laporan-keuanganperbankan/default.aspx

Imam wahyudi, Manajemen Risiko Bank Islam, (Jakarta : Salemba Empat, 2013).

Saparuddin Siregar, Performance Appraisal Pada BPRS, Jurnal Manajemen Bisnis, Volume 1, Nomor 1, Januari 2008.

Peraturan Bank Indonesia Nomor 11/23/PBI/2009 Tentang "Bank Pembiayaan Rakyat Syariah”.

Muhammad, Manajemen Pembiayaan Bank Syariah, (Yogyakarta:UPP AMP YKPN, 2005).

Muhammad, Metodologi Penelitian Ekonomi Islam, Pendekatan Kuantitatif, (Jakarta, PT Raja Grafindo Persada, 2008).

Muhammad Nadratuzzaman Hosen dan Shofaun Nada, Jurnal Pengukuran Tingkat Kesehatan dan Financial Distress Bank Umum Syariah, UIN Syarif Hidayatullah Jakarta, 2014

Muhammad Syafi'i Antonio, Bank Syariah Dari Teori Ke Praktik, (Jakarta: Gema Insani, 2001).

Sudarmanto, R. Gunawan. 2005. Analisis Regresi Ganda dengan SPSS. Edisi Pertama. Bandar Lampung. Graha Ilmu

IBM SPSS 22 Statistik Viewer

Tihendradi, Cornelius. 2012. Step by step SPSS 20 Analisis Data Statistik. Yogyakarta.
Undang-Undang Republik Indonesia Nomor 21 Tahun 2008 Tentang "Perbankan Syariah".

Zuliana Roviqoh, S.E.I, "Pengaruh Tingkat Risiko Pembiayaan Murabahah, Mudharabah dan Musyarakah terhadap Tingkat Profitabilitas 2010-2014", Tesis UIN Sunan Kalijaga 2015. 